\title{
Myopic shift and its mechanism in nephropathia epidemica or Puumala virus infection
}

\author{
Matti Kontkanen, Tuomo Puustjärvi, Juhani Lähdevirta
}

\begin{abstract}
Nephropathia epidemica (NE) is a zoonose caused by Puumala virus. NE belongs to the group of haemorrhagic fevers with renal syndrome. Transient myopia has been described in the acute phase of the disease. This prospective study presents the changes of refraction and the results of ophthalmic $A$ scan measurements of patients who were managed at Savonlinna Central Hospital for NE during an epidemic in the winter of 1992-3. This involved 37 patients and 74 eyes. The incidence of transient myopia was $8 \cdot 1 \%$ and that of myopic shift $40 \cdot 5 \%$. A scan ultrasound measurements were performed in patients in the acute phase and after total recovery of their general illness. Statistical analysis revealed that there were significant differences in anterior chamber depth and lens thickness between the acute and control phases of the disease and between the patients who had myopic shift compared with those who did not have a significant myopic change in refraction. Based on these results it seems that the reason for transient myopic shift of NE is mainly a combination of two factors: forward movement of the anterior diaphragm and thickening of the crystalline lens. The term myopic shift should be used rather than transient myopia because it better describes the overall refractive change in NE.

(Br F Ophthalmol 1994; 78: 903-906)
\end{abstract}

HISTORY, EPIDEMIOLOGY, AND CLINICAL PICTURE OF THE DISEASE

Nephropathia epidemica (NE) has been known since the papers of Myhrman ${ }^{1}$ and Zetterholm. ${ }^{2}$ The causative agent is Puumala virus, ${ }^{3}$ which belongs to Hantavirus genus in the Bunuaviridae family. ${ }^{4}$ Clinically NE is the mildest form (mortality below $0.5 \%$ ) in the group of haemorrhagic fevers with renal syndrome (HFRS). The most severe form (mortality $5-6 \%$ ) is Korean haemorrhagic fever (KHF) caused by the Hantaan virus. The intermediate illness (mortality $1-3 \%$ ) is Seoul virus disease. The most recent disease caused by the newest member of Hantaviruses is the Hantavirus pulmonary syndrome from the USA. ${ }^{56}$ All these diseases are zoonoses. The main reservoir of Puumala virus is the bank vole, Clethrionomys glareolus. Transmission is mainly through the respiratory pathway by dust contaminated by rodent excreta. Puumala virus infection is widespread in Scandinavia and the European part of Russia but also occurs in central and southern Europe. The number of cases of clinical NE seen in Finland is around 1000 annually, with epidemic peaks in autumn and winter. The mean incubation period is 3 weeks. The clinical disease begins with acute high fever lasting 3-5 days, followed by an acute tubular and interstitial nephritis as the main manifestation although it is a general infection. ${ }^{7}$ In non-fatal cases the prognosis is good. A not uncommon ophthalmic peculiarity in the clinical picture is the acute transient myopia beginning in the end phase of fever and lasting from one to several days. ${ }^{7}$

TRANSIENT MYOPIA AND OTHER OPHTHALMIC

MANIFESTATIONS

Transient myopia has often been found in the acute phase of NE. ${ }^{7-9}$ Varying incidences of 12$53 \%$ have been reported. ${ }^{7-9}$ Myopia has been seen with capillary dilatation, interstitial oedema, and haemorrhages in the ciliary body with its anterolateral rotation, relaxation of the zonule, and anterior movement of the lens. ${ }^{8}$ It has been supposed that myopia is caused by the shallowing of the anterior chamber and thickening of the lens, ${ }^{9}$ but there has been no statistically significant evidence of it and the mechanism of transient myopia in NE has remained obscure.

However, the mechanism of the change in refraction by diabetics is better known. The tendency to myopia occurs when the blood glucose is elevated; the opposite trend, towards hyperopia develops when the blood glucose is decreased. ${ }^{10}$ The reason for transient diabetic myopia is presumed to be due to a change in refractive index of the lens. " There is no significant acute change in lens curvature or position. ${ }^{12-14}$ Transient myopia has been described in connection with some pharmaceuticals - for example, quinine,${ }^{15}$ hygroton, ${ }^{16}$ fluocortolon, ${ }^{17}$ acetazolamide ${ }^{1819}$ and some other sulphonamide derivatives - for example, ethoxzolamide ${ }^{20}$ and hydrochlorothiazide. ${ }^{21}$ The reason for pharmaceutical myopia is not clear. Several explanations have been presented: a spasm in cilary muscle, alteration in the shape of the lens and in its refractive index, and swelling of the vitreous cavity with forward movement of the anterior diaphragm. ${ }^{172}$ Parasympathomimetics or paralysis of the sympathetic nerve supply may cause myopic shift in refraction..$^{23} 24$

Other ophthalmic manifestations reported in $\mathrm{NE}$ are lid oedema, conjunctival injection, chemosis, and mild iritis. ${ }^{7-9}$ Some cases of acute glaucoma have been found ${ }^{825}$ although the eyes usually are hypotonic in the acute phase. ${ }^{9}$ There is one report of anisocoria. ${ }^{9}$

\section{Patients and methods}

PATIENTS

Savonlinna Central Hospital is located in eastern 
Finland in a lake district where the incidence of NE is highest in Finland. ${ }^{7}$ During the epidemic of the winter of 1992-3 we had the opportunity to examine the eyes of 43 consecutive patients having suspected acute NE disease. The primary clinical diagnosis of NE was confirmed by an IgG antibody and avidity test against Puumala virus. ${ }^{26}$ Four patients were excluded because of negative serology and two patients neglected the control examination. Finally 37 patients with positive serology were included in this study. There were 18 men and 19 women with mean age $46 \cdot 1(17 \cdot 5)$ years (range 10-85 years; median 45 years).

\section{STUDY AND METHODS} immediately after patients contacted first aid for their general symptoms (acute phase). The patients underwent a control examination after total recovery from their disease (control phase). In both phases complete ophthalmic examination was performed including cycloplegic refraction, gonioscopy, automatic refractokeratometry (Canon RK-1), and ultrasound A scan measurements (Teknar A/B 1992) in cycloplegy. The ultrasound equipment was calibrated weekly and the reproducibility of the measurements was confirmed by measuring both eyes of three healthy test persons during 2 months in seven separate sessions. At least five reliable measurements per eye were taken in each session. The measured ultrasound parameters were anterior chamber depth (ACD), thickness of the lens, axial length (AXL) of the eye, and length of vitreous cavity (VL). The patients were divided into two groups: patients with myopic
An ophthalmic examination was performed shift of $0.5 \mathrm{D}$ or more between acute and control

phases (group 1) and patients with myopic shift less than that (group 2). The ophthalmic examination of the acute phase was performed 1-9 (mean 5.4) days after onset of fever and the control examination 28-175 (mean 64.0) days after first symptoms.

\section{STATISTICAL METHODS AND DATA ANALYSIS}

The results were analysed with non-parametric tests: the Mann-Whitney U test for variables which were not normally distributed and the Wilcoxon matched pairs signed rank test in analyses between group means with a normal distribution; each test was a two tailed one. In evaluating interactions between variables of the groups, correlation analysis was utilised. A p value of $<0.05$ was considered significant.

\section{Results}

\section{REFRACTION}

As Table 1 shows there was a tendency towards myopia in the acute phase. Fifteen patients $(40.5 \%)$ had a refraction change $0.5 \mathrm{D}$ or more (group 1) and 22 patients had myopic refraction change less than that (group 2). The mean myopic shift in group 1 was $0.87 \mathrm{D}$ right eye (range $0.5-3.0 \mathrm{D}$ ) and $0.82 \mathrm{D}$ left eye (range 0.5 $3 \cdot 25 \mathrm{D})$. We found three cases $(8 \cdot 1 \%)$ with real transient myopia. The rest of the patients $(n=12)$ in group 1 had less hyperopia in the acute phase than at the control phase. Two of these hyperopics found visual acuity better in the acute phase than after recovery. Blurred vision was reported by 20 patients $(54 \cdot 1 \%)$. In almost all cases the subjective visual acuity was fully recovered after 1 week.

\section{ANTERIOR CHAMBER DEPTH}

In both groups the anterior chamber was more shallow in the acute phase than after recovery but there were statistically significant differences between the groups. As Table 2 shows the changes in depth were much more prominent in group 1 than in group 2. The differences in anterior chamber depth (ACD) in group 1 between acute and control phases were $11.9 \%$ RE and $10.8 \%$ LE. The corresponding differences in group 2 were $3 \cdot 78 \% \mathrm{RE}$ and $3 \cdot 18 \% \mathrm{LE}$.

Table 2 Comparisons in the anterior chamber depth ( $\mathrm{mm})($ mean $(S D))$ between the phases and the groups

\begin{tabular}{llllll}
\hline & \multicolumn{2}{l}{ Group $l(n=15)$} & & \multicolumn{2}{l}{ Group 2 $(n=22)$} \\
\cline { 2 - 3 } \cline { 5 - 6 } & $R E$ & $L E$ & & $R E$ & $L E$ \\
\hline Acute phase & $2 \cdot 92(0 \cdot 48)$ & $2 \cdot 97(0.47)$ & & $3 \cdot 27(0 \cdot 32)$ & $3 \cdot 30(0 \cdot 35)$ \\
Control phase & $3 \cdot 27(0 \cdot 37)$ & $3 \cdot 29(0.36)$ & & $3 \cdot 39(0 \cdot 30)$ & $3 \cdot 40(0 \cdot 35)$ \\
Differences between two phases & $0 \cdot 35(0 \cdot 27)^{\star}$ & $0 \cdot 32(0 \cdot 28) \dagger$ & & $0 \cdot 12(0 \cdot 09)^{\star}$ & $0 \cdot 10(0 \cdot 14) \dagger$ \\
\hline
\end{tabular}

$\star R E, p<0.001$ between the groups. $\nmid L E, p<0.01$ between the groups.

Table 3 Changes in the thickness $(\mathrm{mm})$ (mean $(S D))$ of the lens

\begin{tabular}{llllll}
\hline & \multicolumn{2}{l}{ Group $1(n=15)$} & & \multicolumn{2}{l}{ Group 2 $(n=22)$} \\
\cline { 2 - 3 } \cline { 5 - 6 } & $R E$ & $L E$ & & $R E$ & $L E$ \\
\hline Acute phase & $4 \cdot 36(0 \cdot 37)$ & $4 \cdot 29(0.37)$ & & $4 \cdot 13(0 \cdot 49)$ & $4 \cdot 11(0.49)$ \\
Control phase & $4 \cdot 18(0 \cdot 35)$ & $4 \cdot 15(0 \cdot 36)$ & & $4 \cdot 06(0 \cdot 47)$ & $4 \cdot 04(0.50)$ \\
Differences between the phases & $0 \cdot 18(0 \cdot 10)^{\star}$ & $0 \cdot 14(0.09) \dagger$ & & $0.07(0.07)^{\star}$ & $0 \cdot 07(0.07) \dagger$ \\
\hline
\end{tabular}

$\star R E$ and $+L E, p<0.01$ between group 1 and group 2 .

In both groups the lens was thicker in the acute phase than after recovery, but there were statistically significant differences between the groups. As Table 3 shows the changes were more prominent in group 1 than in group 2. The differences in the thickness of the lens in group 1 between acute and control phases were $4 \cdot 0 \%$ RE and $3.3 \% \mathrm{LE}$. The corresponding differences in group 2 were $1 \cdot 77 \%$ and $1 \cdot 62 \%$.

\section{VITREOUS LENGTH AND AXIAL LENGTH}

As Tables 4 and 5 show vitreous length (VL) and axial length (AXL) were slightly shorter in the acute phase than in the control phase in both 
Table 4 Changes in the length $(\mathrm{mm})($ mean $(S D))$ of the vitreous cavity

\begin{tabular}{|c|c|c|c|c|}
\hline & \multicolumn{2}{|c|}{ Group $1(n=15)$} & \multicolumn{2}{|l|}{ Group $2(n=22)$} \\
\hline & $R E$ & $L E$ & $R E$ & $L E$ \\
\hline $\begin{array}{l}\text { Acute phase } \\
\text { Control phase } \\
\text { Differences between the phases }\end{array}$ & $\begin{array}{c}15 \cdot 20(0 \cdot 75) \\
15 \cdot 24(0 \cdot 75) \\
0 \cdot 04(0 \cdot 24)^{\star}\end{array}$ & $\begin{array}{c}15 \cdot 17(0 \cdot 77) \\
15 \cdot 23(0 \cdot 76) \\
0.06(0.27) \dagger\end{array}$ & $\begin{array}{l}15 \cdot 67(1 \cdot 02) \\
15 \cdot 78(1 \cdot 03) \\
0 \cdot 11(0 \cdot 10)^{\star}\end{array}$ & $\begin{array}{c}15 \cdot 54(0 \cdot 83) \\
15 \cdot 67(0 \cdot 85) \\
0 \cdot 13(0 \cdot 08) \dagger\end{array}$ \\
\hline
\end{tabular}

$\star$ RE and $+\mathrm{LE}, \mathrm{p}>0.5$ between group 1 and group 2 .

Table 5 The changes in the axial length $(\mathrm{mm})($ mean $(S D))$ of the eye

\begin{tabular}{|c|c|c|c|c|}
\hline & \multicolumn{2}{|c|}{ Group $1(n=15)$} & \multicolumn{2}{|c|}{ Group $2(n=22)$} \\
\hline & $R E$ & $L E$ & $R E$ & $L E$ \\
\hline $\begin{array}{l}\text { Acute phase } \\
\text { Control } \\
\text { Differences }\end{array}$ & $\begin{array}{c}22.48(0.73) \\
22.69(0.67) \\
0.21(0.15)^{\star}\end{array}$ & $\begin{array}{c}22.43(0.78) \\
22.66(0.70) \\
0.23(0.21) \dagger\end{array}$ & $\begin{array}{c}23.07(0.91) \\
23.23(0.88) \\
0.16(0.12)^{\star}\end{array}$ & $\begin{array}{c}22.95(0.74) \\
23 \cdot 11(0.72) \\
0 \cdot 16(0 \cdot 16) \dagger\end{array}$ \\
\hline
\end{tabular}

${ }^{\star} R E, p>0 \cdot 2$ between group 1 and group 2 . $\nmid L E, p>0 \cdot 4$ between group 1 and group 2 .

groups. There were no statistical differences between the groups.

\section{CORRELATIONS}

In group 1 there was a statistically significant correlation between anterior chamber depth and VL. The shallower anterior chamber the more the VL shortens or is non-existent. The $p$ value of the correlation was $<0.01$ in both eyes. There were no statistically significant intragroup correlations between refraction-ACD, refraction-lens, refraction-AXL, refraction-VL, lens-VL, lensAXL, AXL-VL, ACD-lens, and ACD-AXL.

\section{KERATOMETRY}

The cornea was slightly steeper in the acute phase than in the control phase. The changes were statistically significant, $p<0.01 \mathrm{RE}$ and $p<0.05$ LE. Because of the small number of patients $(n=14)$ with keratometry readings we could not perform any reliable intergroup statistics.

\section{CASE REPORT}

In our study we had a 26-year-old woman, who was 7 weeks' pregnant, when she had the first symptoms of NE. Her visual acuity was normal before becoming ill. Two days after the beginning of fever she had blurred vision. On the fourth day she had subjective refraction $-6.0 /$ -5.5 and refraction in cycloplegy -3.75 in both eyes. In the acute phase her visual acuity was slightly reduced $(0 \cdot 7 / 0 \cdot 8)$ with the best spectacle correction. She had moderate lid oedema and chemosis on the conjunctiva. On the 14th day her cycloplegic refraction was $-1 \cdot 0 /-0.75$ and visual acuity 1.0 in both eyes. After 1 month her refraction was $-0.75 /-0.5$ and after 5 months it was the same. She had a normal delivery with a healthy child except for testis retention.

\section{Discussion}

The incidence of transient myopia in NE has been reported to be between 12 and $53 \% .^{7-9}$ Our series of 37 consecutive NE patients needing hospital care had an incidence of transient myopia of $8 \cdot 1 \%$, which is similar to the earlier result $(12 \%)$ from the same area. ${ }^{7}$ Thus, the higher values seem to be too high and may be due to invalid sampling. However, we must emphasise that the real incidence is unknown because the number of milder unhospitalised cases during one epidemic is many times greater, but it seems logical that the incidence should be lower.

Truly transient myopia, however, does not give correct data on the refractive change in $\mathrm{NE}$; the incidence of $40.5 \%$ of myopic shift in our study indicates that myopic change in refraction is common. However, myopic shift was often found only by ophthalmic examination as the patients were mostly hyperopics and they did not have blurred distance vision.

Our ultrasound measurements and keratometry readings showed that myopic change in refraction is caused by variations in three different parameters: position of lens, thickness or shape of the lens, and finally corneal curvature. The most prominent change was the forward movement of the anterior diaphragm or shallowing of the anterior chamber (which probably is the most important factor in myopic shift). Thickening of the lens causes myopic change by steepening of anterior and posterior curvatures of the lens. Steepening of the cornea seems to have some influence on myopic shift, too, but because of the small number of keratometry readings $(n=14)$, it was not considered significant. We found some shortening of axial length of the eye in the acute phase, which has an opposite effect on refraction. Shortening of the AXL may be explained by the general dehydration and ocular hypotension in the acute phase. In young patients the non-cycloplegic refractions may cause myopia as a result of ciliary spasm as is shown in our case history. However, the spasm in the ciliary body is not the basic reason for myopic shift.

But what is the connection between myopic shift and Puumala virus? There is evidence that Puumala virus multiplies in capillary endothelial cells, ${ }^{27}$ which can cause increasing permeability and leakage of osmolar active material as well as of red cells. The leakage of red cells is seen as interstitial haemorrhages in kidneys, heart, lungs, and pituitary gland. We have seen bleeding in the conjunctiva and retina. The changes in osmolarity of aqueous humour and of crystalline lens, and oedema in ciliary body could be a logical explanation of the myopic change in refraction.

There was no significant asymmetry in the ocular changes, which could make the clinical expression of the disease more complicated. Asymmetry in this disease has been found, for example, in renal manifestation measured by isotope nephrography. ${ }^{7}$ In general, we consider the ocular findings and changes to support the original hypothesis ${ }^{7}$ of common capillary endothelial damage as the basic pathogenesis in NE.

Finally, we would like to emphasise from the practical clinical point of view that basic refraction and the amount of myopic shift determine whether the patient becomes truly myopic or not. The term myopic shift covers the refractive changes of NE better than transient myopia, because it is not dependent on basic refraction. 
1 Myhrman G. En njursjukdom med egenartad symptombild. Nord Med Tidskr 1934; 7: 793-4.

2 Zetterholm S. Akuta nefriter simulerande akuta bukfall. Läkartidningen 1934; 31: 425-9.

3 Brummer-Korvenkontio $M$, Vaheri A, Hovi T, von Bonsdorff $\mathrm{CH}$, Vuorimies J, Manni T, et al. Nephropathia epidemica: detection of antigen in bank voles and serologic diagnosis of human infection. $\mathcal{F}$ Infect Dis 1980; 141: 131-4

4 Schmaljohn CS, Hasty SE, Dalrymple JM, LeDuc JW, Lee $\mathrm{HW}$, von Bonsdorff $\mathrm{CH}$, et al. Antigenic and genetic properties of viruses linked to hemorrhagic fever with renal properties of viruses linked to hemorr
syndrome. Science $1985 ; 227: 1041-4$.

5 Nichol ST, Spiropoulou CF, Morzunov S, Rollin PE, Ksiazek TG, Feldmann $\mathrm{H}$, et al. Genetic identification of a hantavirus associated with an outbreak of acute respiratory illness. Science 1993; 262: 914-7.

6 Duchin JS, Koster FT, Peters CJ, Simpson GL, Tempest B, Zaki SR, et al. Hantavirus pulmonary syndrome: a clinical description of 17 patients with a newly recognized disease. NEnglf Med 1994; 330: 949-55.

7 Lähdevirta J. Nephropathia epidemica in Finland. A clinical, histological and epidemiological study. Ann Clin Res 1971;3 (suppl 8): 1-154.

8 Saari KM, Luoto S. Ophthalmological findings in nephropathia epidemica in Lapland. Acta Ophthalmol 1984; 62: pathia 43 .

9 Pärssinen O, Klemetti A, Rossi-Rautiainen E, Forslund T. Ophthalmic manifestations of epidemic nephropathy. Acta Ophthalmol 1993; 71: 114-6.

10 Bloch RS, Henkind P. Ocular manifestations of endocrine and metabolic diseases. In: Tasman W, Gold D, eds. Duane's clinical textbook of ophthalmology. Vol 5. Philadelphia: Lippincott, 1992; 21: 9.

11 Bron AJ, Sparrow J, Brown NAP, Harding JJ, Blakytny R. The lens in diabetes. Eye 1993; 7: 260-75.

12 Planten JT. Physiologic optic approach of lens and cataract. Ophthalmologica 1975; 171: 249-53.

13 Planten JT. Changes of refraction in the adult due to changing refractive indices of the layers of the lens. Ophthalmologica 1981; 183: 86-90.
14 Planten JT, Kooijman AC, De Vries B, Woldringh J. Pathological-optic approach of cataract and lens. Ophthalmologica 1978; 176: 331-4.

15 Segal A, Aisenberg A, Ducasse A. Quinine, myopie transitoire et glaucome par fermeture de l'angle. Bull Soc Ophtalmol Fr 1983; 83: 247-9.

16 Valderrabano E, Leon E, Encinas JL. Miopia transitoria consecutiva a la administracion de higro-tona. Arch Soc Esp Oftal 1976; 36: 269-72.

17 Schröder W, Schwarzer J. Transitorische Myopie mit Winkelblockglaukom (Fallbericht mit echometrische Winkelblockglaukom (Fallbericht mit echometrische 762-6.

18 Muirhead J, Scheie H. Transient myopia after acetazolamide. Arch Ophthalmol 1960; 63: 315 .

19 Galin MA, Baras I, Zweifach P. Diamox-induced myopia. Am f Ophthalmol 1962; 54: 237

20 Beasley FJ. Transient myopia - ethoxzolamide. Arch Ophthalmol 1962; 68: 490.

21 Beasley FJ. Transient myopia and retinal edema during hydrochlorothiazide (Hydrodiuril) therapy. Arch Ophthalmol 1961; 65: 212 .

22 Rohr WD. Transitorische Myopisierung und Drucksteigerung als Medikamentennebewirkung. Tagung Dtsch Ophtalmol Ges Fortschr Ophthalmol 1984; 81: 199-200.

23 Varga E. Transitory myopia occurred under effect of the generally used cholinesterase paralysers. Szemeszet 1981 ; generally

24 Moses RA. Accommodation. In: Moses RA, Hart WM, eds. Adler's physiology of the eye. Clinical application. 8th ed. St Louis: Mosby, 1987: 309.

25 Saari KM. Acute glaucoma in haemorrhagic fever with renal syndrome. Am F Ophthalmol 1976; 81: 455-61.

26 Hedman K, Vaheri A, Brummer-Korvenkontio M. Rapid diagnosis of Hantavirus disease by an avidity assay for IgC antibody. Lancet 1991; 338: 1353-6.

27 Cosgriff TM. Mechanism of disease in Hantavirus infection: pathophysiology of hemorrhagic fever with renal syndrome. Rev Infect Dis 1991; 13: 97-107. 